\title{
BMJ Open Estimating the return on investment of the Bureau of Tobacco Free Florida tobacco control programme from 1999 to 2015
}

\author{
James Nonnemaker (D) , ${ }^{1}$ Anna J MacMonegle, ${ }^{1}$ Nathan Mann, ${ }^{1}$ Robyn Woodlea, ${ }^{1}$
} Jennifer Duke, ${ }^{1}$ Lauren Porter $^{2}$

To cite: Nonnemaker J, MacMonegle AJ, Mann N, et al. Estimating the return on investment of the Bureau of Tobacco Free Florida tobacco control programme from 1999 to 2015. BMJ Open 2021;11:e040012. doi:10.1136/ bmjopen-2020-040012

- Prepublication history and supplemental material for this paper is available online. To view these files, please visit the journal online (http://dx.doi. org/10.1136/bmjopen-2020040012).

Received 07 May 2020 Revised 14 0ctober 2020 Accepted 22 December 2020

Check for updates

(C) Author(s) (or their employer(s)) 2021. Re-use permitted under CC BY-NC. No commercial re-use. See rights and permissions. Published by BMJ.

${ }^{1}$ Center for Health Analytics, Media, and Policy, RTI International, Research Triangle Park, North Carolina, USA

${ }^{2}$ Bureau of Tobacco Free Florida, Florida Department of Health, Tallahassee, Florida, USA

Correspondence to Dr James Nonnemaker; jnonnemaker@rti.org

\section{ABSTRACT}

Objective To assess the return on investment (ROI) of the Florida tobacco control programme, the Bureau of Tobacco Free Florida (BTFF), in terms of healthcare expenditure savings and mortality cost saved as a result of reduced mortality due to the programme from 1999 to 2015.

Methods We use a synthetic control method to estimate the impact of the BTFF on smoking-attributable mortality, years of life lost (YLL), healthcare expenditures, and the economic value of premature mortality due to smoking in Florida from 1999 through 2015. We calculated an ROI for healthcare expenditures and for the value of life years saved.

Results From 1999 to 2015, adult smoking prevalence in Florida averaged 0.98 percentage points lower than prevalence in the synthetic control states $(19.6 \%$ vs 20.6\%). The ROI over the period from 1999 to 2015 was 9.61 for healthcare expenditures and 112.44 for premature mortality. These ROls suggest that for every US\$1 of expenditure by BTFF, smoking-attributable healthcare expenditures decreased by almost US\$11 and reductions in the economic costs associated with YLL due to smoking-attributable mortality totaled approximately US\$113.

Conclusions Our results suggest the BTFF resulted in fewer YLL, substantial healthcare cost savings and substantial savings in terms of mortality costs. The positive ROls for healthcare expenditures and premature mortality suggest that the BTFF is a good investment of public funds.

\section{BACKGROUND}

The Bureau of Tobacco Free Florida (BTFF) is one of the largest statewide tobacco control programmes in the USA. The programme's goal is to protect people from the health hazards of using tobacco by discouraging tobacco use. The programme began in 1998 as the result of a lawsuit settlement with tobacco companies to cover costs of smoking to the state's Medicaid programme. BTFF funded a youth-focused media campaign, a statewide youth empowerment programme, Students Working Against Tobacco, local community
Strengths and limitations of this study

- Our study uses a synthetic control group method to establish the effectiveness of the Bureau of Tobacco Free Florida (BTFF).

- We estimate the return on investment of BTFF expenditures in terms of smoking-attributable healthcare expenditure savings and reductions in premature smoking-attributable mortality.

- A limitation of our study is that the synthetic control group is not a perfect fit for Florida in the period prior to the start of the BTFF and that the synthetic control group had some tobacco control funding in the period after the start of the BTFF.

- Another limitation is that we do not consider all possible costs of smoking.

partnerships, and promoted curriculumbased tobacco use prevention education. The youth-focused media campaign has been shown to be associated with declines in youth smoking. ${ }^{1-3}$ Annual programme funding ranged from US $\$ 17$ to US\$49 million between 1999 and 2003 and dropped to less than US\$1 million from 2004 to 2006. Several studies showed that the funding reductions from 2004 to 2006 reduced the effect of the programme. ${ }^{4}$ Funding was fully restored in 2007 as the result of a state constitutional ballot initiative, and BTFF began to administer the programme consistent with the recommendations from the Centers for Disease Control and Prevention (CDC) Best Practices for Comprehensive Tobacco Control Programs. From 2008 to 2015, annual allocations to a comprehensive statewide tobacco programme ranged from US $\$ 52$ to US\$67 million, and Florida was ranked among the top 15 states in reaching the CDC's recommended funding levels. ${ }^{6}$ Since 2007, BTFF consists of the five programme components of a comprehensive tobacco 
control programme: state and community; mass-reach health communications; cessation; surveillance and evaluation; and infrastructure, administration and management. Studies have shown that the BTFF media campaign has increased use of state-sponsored cessation services, increased population-level quit attempts statewide and reduced relapse among quitters in Florida. ${ }^{7-9}$

Several studies have also examined the impact of tobacco control programmes in terms of healthcare expenditure savings resulting from reductions in prevalence relative to programme expenditures. A study by Dilley et $a l^{10}$ compared smoking prevalence in Washington with the national average to determine the effectiveness of the tobacco control programme. They found that during a 10-year period of funding for the state tobacco control programme in Washington, the state saved US $\$ 5.73$ in costs associated with fewer hospitalisations for every US $\$ 1$ spent by the programme. A study by Richard et $a l^{11}$ examined the return on investment (ROI) of a Medicaid tobacco cessation programme in Massachusetts. They found an ROI of 2.12 in terms of medical care savings. ${ }^{11}$

Lightwood and Glantz ${ }^{12}{ }^{13}$ estimated the impact of the California and Arizona tobacco control programmes in terms of healthcare expenditure savings from reductions in smoking prevalence and reductions in consumption. In both analyses, they used a control group of 38 states that did not have substantial tobacco control programmes or tobacco taxes of 50 cents per pack or more. They found that in California, the tobacco control programme resulted in healthcare expenditure savings of US $\$ 50$ for every US $\$ 1$ of programme spending. In Arizona, they found a ratio of healthcare expenditure savings to programme spending of 10 to 1 .

Abadie $e t a l^{14}$ used a synthetic control method to assess Proposition 99 in California. They found that after Proposition 99 passed, tobacco consumption declined in California relative to a synthetic comparison group for California. In Abadie, the authors argue for the importance of using a synthetic comparison group (ie, in using data-driven methods to select a comparison group vs using, eg, the rest of the USA as the comparison group) in such analyses.

In this paper, we assess the ROI of the BTFF in terms of (1) healthcare expenditure savings-a measure of direct costs saved due to programme expenditures from 1999 to 2015, and (2) mortality costs saved as a result of reduced mortality due to the programme-a measure of the indirect costs saved due to programme expenditures from 1999 to 2015.

\section{METHODS}

\section{Data}

To conduct our synthetic control analysis, we used data from CDC's Behavioral Risk Factor Surveillance System for 1991 to $2015 .{ }^{15}$ We used data on state demographics (age and gender distributions) obtained from the US
Census. ${ }^{16-19}$ We obtained state-specific income and poverty levels from the Annual Social and Economic Supplement of the Current Population Survey. ${ }^{20}$

We used data from CDC's recommended funding levels from $2014^{6}$ to identify state-specific funding recommendation thresholds. We updated this data to yearspecific funding recommendations for each state for 1999 through 2015, adjusted using the consumer price index (CPI). Data on state tobacco control programme funding was collected by RTI International. Tobacco control programme funding data reflect funding from federal (eg, CDC's National Tobacco Control Program), state (eg, revenues from cigarette taxes, revenues from the Master Settlement Agreement), and non-government (eg, Robert Wood Johnson Foundation, American Legacy Foundation) sources.

We obtained annual estimates of both total and smokingattributable mortality as well as average remaining life expectancy in Florida for the years 1999 through 2015 from the 2017 Global Burden of Disease (GBD) study. ${ }^{22}$ These data capture premature mortality and disability from more than 300 diseases and injuries by geography, year, age and gender. We obtained data on nominal annual healthcare expenditure data by state of residence and type of medical care for 1991 through 2014 from The Centers for Medicare and Medicaid Services (CMS) ${ }^{23}$

\section{Analysis}

\section{Synthetic control estimation}

To estimate the impact of BTFF funding on smoking prevalence, we used a synthetic control method ${ }^{14}$ to compare adult smoking prevalence in Florida with a synthetic control. The synthetic control method essentially creates a comparison group for Florida that best matches the adult smoking prevalence trend in Florida in the period prior to implementation of the BTFF programme (the pretreatment period, which in our analysis is the years 1991-1998). The synthetic control group represents what the trend in Florida adult smoking prevalence would have been in the posttreatment period (1999-2015) had there been no BTFF in Florida. To construct a synthetic comparison for Florida, the synthetic control method combined a set of states to form the synthetic control based on predictors of adult smoking prevalence. We used as predictors the percentage of the population aged 18+, the percentage of the population that is male, the percentage of the population that reported making a quit attempt in the past year, the median income of the state, the poverty rate, the percentage of respondents who reported drinking in the past week, and the percentage of adults who reported exercising any in the past week. These variables were averaged over the 1991-1998 period and augmented by adding 3 years of lagged smoking prevalence: 1991, 1995 and 1998. To identify states for the control group that did not have significant levels of tobacco control programme funding we compared the CDC-recommended funding levels for each state with the state's level of tobacco control programme funding. We used the Stata package synth ${ }^{24}$ to conduct the synthetic control analysis for the selected states. The model with the lowest 
Table 1 Comparison of Florida with synthetic control across predictor variables

\begin{tabular}{lll}
\hline Variable & Florida & $\begin{array}{l}\text { Synthetic } \\
\text { control }\end{array}$ \\
\hline \% Current smoker (1998) & 22.0 & 22.9 \\
\hline \% Current smoker (1995) & 23.2 & 23.1 \\
\hline \% Current smoker (1991) & 25.0 & 24.1 \\
\hline \% Population male & 48.6 & 48.7 \\
\hline \% Population over 18 & 77.5 & 74.4 \\
\hline \% Made a quit attempt & 49.6 & 49.1 \\
\hline Median income & 48605 & 56844 \\
\hline Poverty rate (\%) & 15.2 & 13.8 \\
\hline Drink any in the past week (\%) & 54.1 & 48.6 \\
Exercised any in the past week & 71.7 & 69.4 \\
(\%) & & \\
\hline
\end{tabular}

mean-squared predicted error (MSPE) included smoking lags, $\%$ male, $\%$ population $18+, \%$ quit attempts, median income, poverty rate, $\%$ drink and $\%$ exercise (see online supplemental appendix 1 for more details).

The results indicated that the smoking trends in Florida, in the period before programme funding began, are best reproduced by a combination of Alabama (21\%), Michigan (15.6\%), New Jersey (31.8\%), Tennessee (11.2\%) and Texas (20.5\%). See online supplemental appendix 1 for a list of potential control states included in the model and the relative weights of each state used to construct the synthetic control for Florida. States with a zero weight are not part of the synthetic control.

Table 1 contains the comparison of Florida with the synthetic control for the selected predictor variables. The pretreatment characteristics in Florida are closely mirrored by the synthetic control. Online supplemental appendix 1 also provides a comparison of Florida and the synthetic control states on several tobacco control policy measures (cigarette excise taxes and clean indoor air laws).

We conducted placebo tests for our selected synthetic control model following the procedure outlined in Abadie $e t$ $a l^{14}$ For the placebo tests, we replace Florida with each potential donor to the synthetic control group, placing Florida in the donor pool as a potential control state, and re-estimate the synthetic control model. We then calculate the ratio of the MSPE in the postprogramme period to the MSPE in the preprogramme period. This results in 13 tests in our case. We compare the ratio of pre-MSPE to post-MSPEs in Florida to those for each potential donor to the synthetic control (see online supplemental appendix 1).

We also conducted a sensitivity analysis. For this, we conducted the synthetic control estimation and calculated the ROI for each of six model specifications which had the next six lowest MSPEs compared with our selected model. This creates a new synthetic control group and then compares Florida to the new synthetic control created. We report the mean and median ROIs across these six models (see online supplemental appendix 1). This gives us six new ROIs and is a measure of the sensitivity of our results to the specific model and synthetic control group we create.

\section{Smoking-attributable costs}

Smoking-attributable healthcare expenditures (direct costs)

We estimated total healthcare expenditures in Florida in 2015 based on the average annual growth in total healthcare expenditures in Florida over the last 10 years of available CMS data (2004-2014). We adjusted nominal annual total healthcare expenditures in Florida for the years 1999 through 2015 for inflation using the national CPI for medical care produced by the Bureau of Labor Statistics. ${ }^{25}$ All healthcare expenditures presented in this paper are expressed in real, inflation-adjusted, 2015 dollars. We calculated annual smoking-attributable healthcare expenditures in Florida by multiplying inflation-adjusted total annual healthcare expenditures in Florida by annual estimates of the smokingattributable fraction (SAF) for healthcare expenditures in Florida. We obtained estimates of the SAF of healthcare expenditures in Florida in 1993 from Miller et al. ${ }^{26}$ They calculated SAFs based on a two-part model of annual individual expenditures estimated using the 1987 National Medical Expenditure Survey.

Because new estimates of SAF specific to Florida are not readily available and are difficult to obtain given the data requirements for producing such estimates, we adjusted the 1993 SAF for Florida to account for changes in adult smoking prevalence in Florida over the years from 1994 through 2015. The SAF estimates reported by Miller $e t a t^{26}$ exclude healthcare expenditures for dental care. We follow that approach and exclude healthcare expenditures for dental services from our analysis.

\section{Smoking-attributable mortality (indirect costs)}

The SAF for smoking-attributable mortality represents the fraction of total deaths in Florida that were due to smoking. Using GBD data on total and smoking-attributable mortality in Florida, we derived the SAF of mortality associated with smoking in Florida for each gender, 5-year age group, and each of the 33 specific causes included in our analytic data. We calculated smoking-attributable years of life lost (YLL) using GBD data on smoking-attributable deaths (SAD) in Florida as well as GBD data on average remaining life expectancy by gender and 5-year age group. To calculate YLL, we multiplied the annual number of SAD for each gender and 5 -year age group by the average remaining life expectancy for that gender and 5-year age group.

\section{Estimating the economic value of premature mortality due to smoking in Florida}

We calculated the economic value of premature mortality due to smoking in Florida using a value of a statistical life year approach. We used a life year (LY) value of US $\$ 200000 .{ }^{27}$ We updated this for inflation using the CPI to US\$235135 in real, inflation-adjusted, 2015 dollars. Consistent with the US Food and Drug Administration practice, we used a social discount rate of $3 \%$ in calculating $\mathrm{LY}$ values. ${ }^{28}$ 


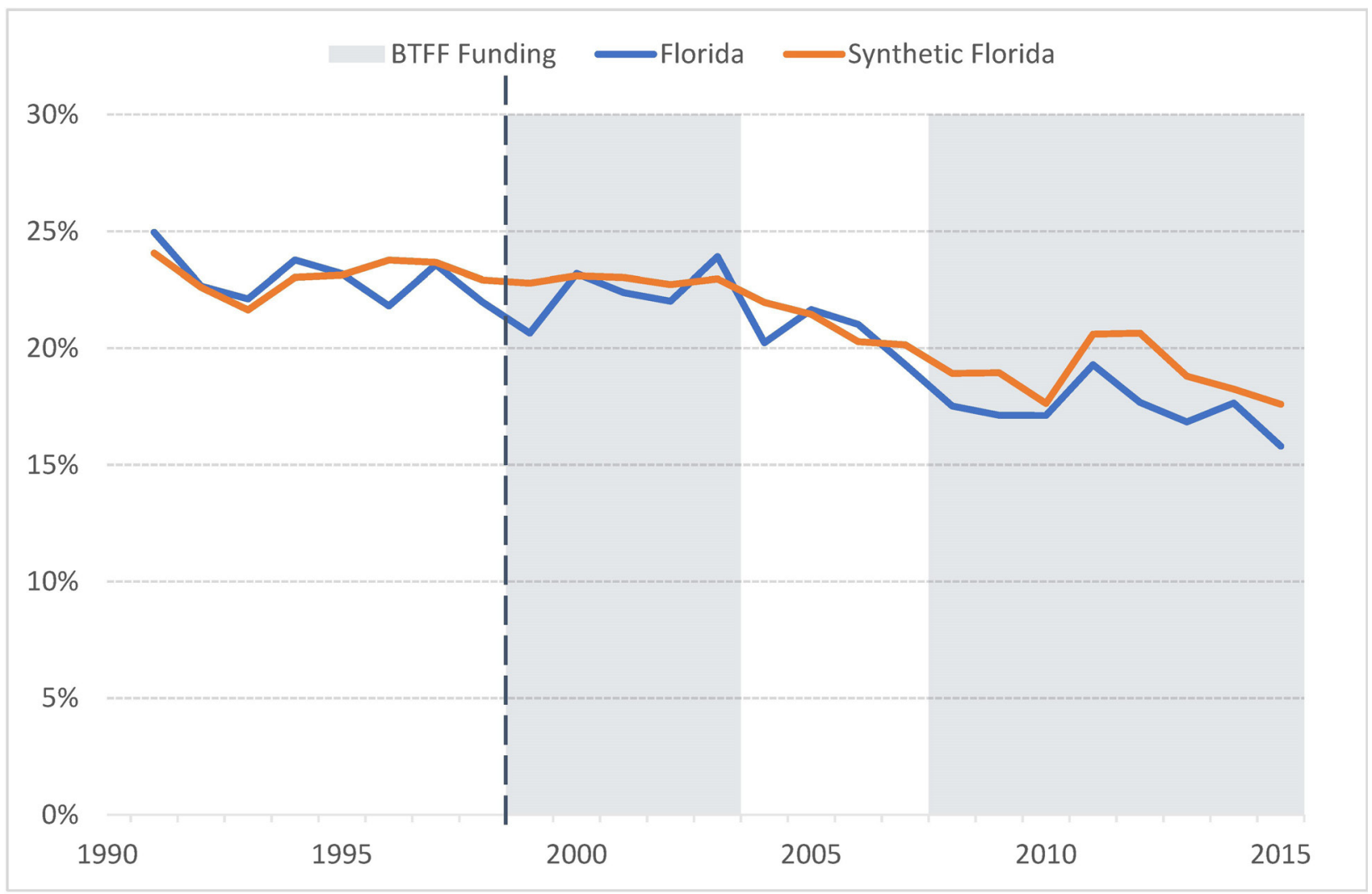

Figure 1 Results of the synthetic control analysis. BTFF, Bureau of Tobacco Free Florida.

Estimating the impact of the BTFF on SAD and costs

To estimate the impact of the BTFF on SAD, YLL, healthcare expenditures, and the economic value of premature mortality due to smoking in Florida from 1999 through 2015, we took the difference in each of those smokingattributable outcomes in Florida between the synthetic control and the estimates for Florida based on estimates of adult smoking prevalence.

\section{$\mathrm{ROI}$}

We calculated the ROI for healthcare expenditure savings and for the value of LYs saved. The ROI was calculated as the net savings divided by programme costs, where net savings is the difference between the value of healthcare expenditures or LYs saved as a result of the programme and the programme costs. For healthcare expenditures and mortality costs (valuation of LY saved), we calculated the cumulative total by summing annual values, as well as tobacco control programme expenditures, from 1999 to 2015 .

\section{Patient and public involvement}

No patients were involved in this study.

\section{RESULTS}

\section{Synthetic control}

Figure 1 shows the annual adult smoking prevalence in Florida and the synthetic control for the analysis period (1991 through 2015). The years in which the BTFF was funded is indicated by the grey shading. The average smoking rate in Florida was $23.0 \%$ in the pretreatment period (1991-1998), compared with $23.1 \%$ in the synthetic control during the same time period. In 2004 before the defunding of the BTFF, the smoking rate was $20.2 \%$ in Florida compared with $22.0 \%$ in the synthetic control. During the years that the BTFF was refunded (2008-2015), the average smoking rates in Florida and the synthetic control were $17 . \%$ and $18.9 \%$, respectively. The smoking prevalence in the synthetic control is consistently higher than in Florida for all years following refunding. The full prevalence estimates can be found in online supplemental appendix 1. Our estimate of the effect of the BTFF on adult smoking prevalence is the difference between prevalence in Florida compared with the synthetic control in the post-treatment period (19992015). We use this estimated reduction in smoking prevalence to quantify the cost savings in Florida resulting from the tobacco control programme.

Following the model selection, we performed placebo tests as described above in methods (See online supplemental appendix 1). We found that of the 13 placebo tests conducted, the MSPE ratio for FL was larger than 11 of the MSPE ratios for synthetic control states, that is, Florida in a sense passed 11 of 13 placebo tests. We interpret these results to suggest that the difference observed in smoking prevalence between Florida and synthetic Florida was likely a result of the Florida BTFF. We also conducted a sensitivity analysis in which we conducted the synthetic 
Table 2 Smoking-attributable healthcare expenditures in Florida, 1999-2015

\begin{tabular}{|c|c|c|c|c|c|c|}
\hline \multirow[b]{2}{*}{ Year } & \multirow{2}{*}{$\begin{array}{l}\text { Total healthcare } \\
\text { expenditures } \\
\text { (Real US\$ 2015)* }\end{array}$} & \multicolumn{2}{|c|}{$\begin{array}{l}\text { Smoking-attributable fraction } \\
\text { of healthcare expenditures } \\
\text { (SAF) }\end{array}$} & \multicolumn{3}{|c|}{$\begin{array}{l}\text { Smoking-attributable healthcare expenditures (SAE) } \\
\text { (Real US\$ 2015) }\end{array}$} \\
\hline & & $\begin{array}{l}\text { Actual } \\
\text { (\%) }\end{array}$ & $\begin{array}{l}\text { Synthetic control } \\
(\%)\end{array}$ & $\begin{array}{l}\text { Actual } \\
\text { (US\$) }\end{array}$ & $\begin{array}{l}\text { Synthetic control } \\
\text { (US\$) }\end{array}$ & $\begin{array}{l}\text { Difference } \\
\text { (US\$) }\end{array}$ \\
\hline 1999 & 111384956770 & 6.54 & 7.24 & 7288507407 & 8066891693 & 778384286 \\
\hline 2000 & 117032600971 & 7.37 & 7.34 & 8624614265 & 8587439203 & (37 175 061) \\
\hline 2001 & 121373108153 & 7.12 & 7.31 & 8636053625 & 8867376490 & 231322865 \\
\hline 2002 & 125192260103 & 6.99 & 7.21 & 8748729706 & 9027098378 & 278368672 \\
\hline 2003 & 130697915944 & 7.59 & 7.31 & 9922278254 & 9548635977 & (373 642 277) \\
\hline 2004 & 136212563609 & 6.42 & 6.99 & 8740039081 & 9518854445 & 778815364 \\
\hline 2005 & 140287342010 & 6.89 & 6.83 & 9669923963 & 9580800240 & (89 123 723) \\
\hline 2006 & 144855575860 & 6.67 & 6.45 & 9662719001 & 9340628368 & (322 090 633) \\
\hline 2007 & 147036455099 & 6.13 & 6.38 & 9014199618 & 9387845198 & 373645580 \\
\hline 2008 & 149108792106 & 5.56 & 6.00 & 8288694620 & 8951790190 & 663095570 \\
\hline 2009 & 152016527039 & 5.43 & 6.04 & 8257180063 & 9174644514 & 917464451 \\
\hline 2010 & 152070252135 & 5.43 & 5.59 & 8260098284 & 8501621625 & 241523342 \\
\hline 2011 & 151672788801 & 6.13 & 6.54 & 9298434146 & 9924753545 & 626319398 \\
\hline 2012 & 152493109125 & 5.62 & 6.54 & 8573700806 & 9978431446 & 1404730641 \\
\hline 2013 & 151612441195 & 5.34 & 5.97 & 8090753332 & 9053938253 & 963184921 \\
\hline 2014 & 158129242447 & 5.59 & 5.78 & 8840354825 & 9141730557 & 301375733 \\
\hline 2015 & 162632502473 & 5.02 & 5.59 & 8162238301 & 9092113550 & 929875249 \\
\hline Annual avg. & 141400496108 & 6.23 & 6.54 & 8710501135 & 9161446687 & 450945552 \\
\hline Total & 2403808433840 & & & 148078519296 & 155744593672 & 7666074376 \\
\hline
\end{tabular}

${ }^{\star}$ Excluding dental care expenditures.

control analysis and calculated the ROI for each of the six models which had the next lowest MSPE's for the comparison of smoking prevalence in Florida to the synthetic control group in the preprogramme period (see online supplemental appendix 1). These results show that the average ROI across these different models (each would compare Florida to a different selected synthetic Florida) was 5.7 (compared with our estimate from the best model of 9.6) for healthcare utilisation and 52.9 (compared with our estimate of 112.4) for mortality.

\section{Smoking-attributable costs}

\section{Healthcare (direct) costs}

Table 2 presents annual estimates of both total and smoking-attributable healthcare expenditures in Florida for the years 1999 through 2015. Smoking-attributable healthcare expenditures in Florida are presented for adult smoking prevalence in Florida and the synthetic control over those years. In 2015, smoking-attributable healthcare expenditures in Florida were estimated to be approximately US $\$ 8.16$ billion. Had adult smoking prevalence remained at the higher level estimated by the synthetic control, smoking-attributable healthcare expenditures in Florida in 2015 would have been an estimated US $\$ 9.09$ billion. The reduction in adult smoking in Florida in 2015, when compared with the synthetic control, represents a savings of nearly US $\$ 929.9$ million in direct healthcare expenditures in Florida in 2015. The average annual savings in smoking-attributable healthcare expenditures in Florida from 1999 through 2015 was nearly US $\$ 451$ million. Cumulatively, the reductions in adult smoking prevalence in Florida from 1999 through 2015 , compared with the synthetic control, amount to nearly US $\$ 7.67$ billion in smoking-attributable healthcare expenditures.

\section{Mortality (indirect) costs}

Table 3 presents SAD and the YLL due to SAD. Over the years 1999-2015, there were an estimated 544121 SAD in Florida. SAD in Florida from 1999 to 2015 resulted in an estimated 8384783 YLL due to premature mortality. Had adult smoking prevalence in Florida been equal to the levels from the synthetic control over the years 19992015, there would have been an estimated 573127 SAD in Florida, leading to an estimated 8836184 YLL. The difference in adult smoking prevalence in Florida over the years 1999-2015, compared with the synthetic control prevalence, resulted in an estimated $29006 \mathrm{SAD}$ averted in Florida during the years 1999-2015 resulting in an estimated 451402 YLL averted as a result of BTFF funding. 
Table 3 Smoking-attributable deaths (SAD) and years of life lost (YLL) in Florida, 1999-2015

\begin{tabular}{llll}
\hline Outcome & Actual & Synthetic control & Difference (synthetic control-Florida) \\
\hline SAD & 544121 & 573127 & 29006 \\
Smoking-attributable YLL & 8384783 & 8836184 & 451402 \\
$\begin{array}{l}\text { Economic value of smoking- } \\
\text { attributable years of life lost }\end{array}$ & US\$1.52 trillion & US\$1.61 trillion & US\$81.93 billion \\
\hline
\end{tabular}

Table 3 presents estimates of the economic value of the YLL due to SAD. Over the years 1999-2015, the economic value of the YLL due to SAD in Florida was approximately $\$ 1.52$ trillion. Had adult smoking prevalence remained at the higher level that we estimated for the synthetic control, the economic value of the YLL due to SAD in Florida over the years 1999-2015 would have been an estimated $\$ 1.61$ trillion. The reductions in adult smoking prevalence in Florida, compared with the synthetic control, resulted in an estimated savings in the economic value of YLL due to SAD of approximately $\$ 81.93$ billion over the years 1999-2015.

\section{Return on investment}

The ROI results are summarised in table 4. From 1999 through 2015, smoking-attributable healthcare expenditures in Florida were nearly US $\$ 7.7$ billion lower than they would have been had adult smoking prevalence in Florida remained at the higher level of the synthetic control. Over that same period, Florida spent a total of US\$722.3 million on its tobacco control programme (in real, inflation-adjusted, 2015 dollars). The ROI for smoking-attributable healthcare expenditures in Florida from 1999 through 2015 was nearly 10:1. In terms of the economic value of the YLL due to SAD, the ROI in Florida from 1999 to 2015 was approximately 112:1. These ROIs suggest that for every US $\$ 1$ of expenditure by BTFF from 1999 to 2015 , over the same period smoking-attributable healthcare expenditures decreased by almost US $\$ 11$ and the economic cost of LY lost due to SAD decreased by approximately US $\$ 113$.

\section{DISCUSSION}

This study contributes to the literature providing evidence on the effectiveness and efficiency for comprehensive state tobacco control programmes. While there is evidence that state tobacco control programmes reduce tobacco use and programme components are cost effective, few studies have reported on their ROI. State tobacco control programmes likely vary in the funding levels, implementation and effectiveness given their different sociodemographic and economic contexts.
Thus, state-specific assessments are necessary to determine effectiveness, build support for programmes and provide useful information to decision-makers in a state. This study has relevance for building the case for comprehensive state tobacco control programmes in general as well as for decision-makers in the state of Florida.

Our results suggest that the BTFF had a significant role in reducing smoking prevalence. The difference in reductions of smoking prevalence between Florida and the synthetic control was greater following the refunding of the programme in 2007. These reductions in smoking prevalence translated into substantial savings of healthcare expenditures, reductions in smoking-attributable mortality and YLL, and the economic costs associated with reductions in premature smoking-attributable mortality. We also found positive ROIs for the FL BTFF programme in terms of both healthcare expenditures and mortality. Study results suggest that the BTFF programme generated savings or cost reductions in excess of programme expenditures.

Our results are consistent with other studies finding a positive ROI for tobacco control programmes suggesting they are worthwhile investments of public money and generate substantially more savings than are spent to fund the programme. The ROIs we estimate for the BTFF programme also compare favourably to other public health interventions. A review of ROI studies of public health interventions found a median ROI across all interventions of $14.1{ }^{29}$ Our estimated ROI in terms of healthcare expenditures is close to this median value across all interventions while our estimated ROI for mortality (economic valuation of YLL) is considerably higher.

As with any study of this type, our study has several limitations. First, although we created a synthetic control for Florida, our synthetic control states had some levels of tobacco control expenditures. An ideal control would have had no funding. However, this suggests that our estimate of the ROI is conservative and if we had only states with no funding, we would have found a larger ROI for Florida. Second, our method is based on a comparison of adult smoking prevalence in Florida to a synthetic control assuming the control represents what adult smoking

Table 4 Healthcare and mortality return on investment (ROI)

\begin{tabular}{lllll}
\hline Category & Savings & Programme costs & Net savings \\
\hline Healthcare & US\$7 666 074 376 & US\$722260109 & US6\$943814 268 \\
Mortality & US\$81930 432 902 & US\$722260109 & US\$81208 172 793 \\
\hline
\end{tabular}


prevalence would have been in Florida with no tobacco control programme. Since we do not control explicitly for cigarette excise taxes, clean indoor air laws, or other factors that might influence smoking prevalence, if there were differences in these policies between Florida and the synthetic control in the post-treatment period, we might have overestimated or underestimated the effectiveness of the Florida programme. In online supplemental appendix 1, we compare Florida to the synthetic control group on these tobacco control policies. The synthetic control had more tax increases and a higher tax level in the post period than Florida. Florida had a higher percentage of its population covered by workplace and restaurant clean indoor air laws but less of the population covered by smoke-free bars compared with the synthetic control. These results show that synthetic control states implemented tobacco control policies in the period after the start of the Florida BTFF and thus supports our contention that our estimated ROI for the FL BTFF is likely an underestimate. Third, the synthetic control was not a perfect fit for the trend in smoking prevalence for Florida in the pretreatment period. Any difference in trend in the pretreatment period could bias estimates of differences in smoking prevalence between Florida and the synthetic control and thus of the ROI. A simple regression model of smoking prevalence in Florida and synthetic control in the preprogramme period suggests that slopes are relatively flat and not significantly different (results not shown). Fourth, we also do not consider all possible costs of smoking, for example, secondhand smoke costs are not included. Inclusion of these costs would increase the estimated ROI since reductions in smoking prevalence would increase savings resulting from secondhand smoke healthcare expenditures and mortality. Finally, our data on the SAF for healthcare expenditures are dated, though it is Florida specific. ${ }^{26}$ While a more recent estimate of an SAF for healthcare expenditures is available for the total USA, ${ }^{30}$ a recent estimate for Florida is not available. However, the national estimate is similar to the Florida estimate we use.

A positive ROI suggests to decision-makers that a programme or intervention is a good investment. For programme decision-makers and stakeholders, understanding state-specific ROI is critical because the available measures of costs and benefits for ROI calculations vary too widely across states to be interpreted and used by an individual state. This paper suggests that the BTFF is a good investment of public funds. In an environment, where policy-makers are faced with making difficult choices, the results of this study suggest that significant cuts in funding to the BTFF could result in additional costs in terms of healthcare expenditures and premature mortality.

Contributors JN developed the study concept and design with contributions from AJM and NM. RW, AJM and NM conducted all analyses. JN wrote the first draft of the manuscript with contributions from AJM, NM, RW, JD and LP. All authors contributed to and have approved the final manuscript.
Funding Funding for this study was provided by a contract with the Florida Department of Health, contract no. COTGC.

Competing interests None declared.

Patient consent for publication Not required.

Ethics approval This study only used publicly available data with no personally identifiable information and thus does not involve research with human subjects.

Provenance and peer review Not commissioned; externally peer reviewed.

Data availability statement № data are available. The data we used for our study are identified in the manuscript as well as a description of the methods used. Additional details are available upon request.

Supplemental material This content has been supplied by the author(s). It has not been vetted by BMJ Publishing Group Limited (BMJ) and may not have been peer-reviewed. Any opinions or recommendations discussed are solely those of the author(s) and are not endorsed by BMJ. BMJ disclaims all liability and responsibility arising from any reliance placed on the content. Where the content includes any translated material, BMJ does not warrant the accuracy and reliability of the translations (including but not limited to local regulations, clinical guidelines, terminology, drug names and drug dosages), and is not responsible for any error and/or omissions arising from translation and adaptation or otherwise.

Open access This is an open access article distributed in accordance with the Creative Commons Attribution Non Commercial (CC BY-NC 4.0) license, which permits others to distribute, remix, adapt, build upon this work non-commercially, and license their derivative works on different terms, provided the original work is properly cited, appropriate credit is given, any changes made indicated, and the use is non-commercial. See: http://creativecommons.org/licenses/by-nc/4.0/.

\section{ORCID iD}

James Nonnemaker http://orcid.org/0000-0003-1044-7482

\section{REFERENCES}

1 Sly DF, Heald GR, Ray S. The Florida "truth" anti-tobacco media evaluation: design, first year results, and implications for planning future state media evaluations. Tob Control 2001;10:9-15.

2 Sly DF, Hopkins RS, Trapido E, et al. Influence of a counteradvertising media campaign on initiation of smoking: the Florida "truth" campaign. Am J Public Health 2001;91:233-8.

3 Sly DF, Trapido E, Ray S. Evidence of the dose effects of an antitobacco counteradvertising campaign. Prev Med 2002;35:511-8.

4 Davis KC, Crankshaw E, Farrelly MC, et al. The impact of state tobacco control program funding cuts on teens' exposure to tobacco control interventions: evidence from Florida. Am J Health Promot 2011;25:176-85.

5 Niederdeppe J, Farrelly MC, Hersey JC, et al. Consequences of dramatic reductions in state tobacco control funds: Florida, 19982000. Tob Control 2008;17:205-10.

6 Centers for Disease Control and Prevention (CDC). Best practices for comprehensive tobacco control programs-2014. Atlanta, GA: U.S. Department of Health and Human Services, Centers for Disease Control and Prevention, National Center for Chronic Disease Prevention and Health Promotion, Office on Smoking and Health, 2014. https://www.cdc.gov/tobacco/stateandcommunity/best practices/pdfs/2014/comprehensive.pdf

7 Duke JC, Mann N, Davis KC, et al. The impact of a state-sponsored mass media campaign on use of telephone Quitline and web-based cessation services. Prev Chronic Dis 2014;11:E225.

8 Duke JC, Woodlea R, Arnold KY, et al. Effect of a statewide media campaign on smoking cessation among Florida adults. Prev Chronic Dis 2020;17:190271.

9 Nonnemaker JM, Dench D, Homsi G, et al. The effect of exposure to media campaign messages on adult cessation. Addict Behav 2015;49:13-19.

10 Dilley JA, Harris JR, Boysun MJ, et al. Program, policy, and price interventions for tobacco control: quantifying the return on investment of a state tobacco control program. Am J Public Health 2012;102:e22-8.

11 Richard P, West K, Ku L. The return on investment of a Medicaid tobacco cessation program in Massachusetts. PLoS One 2012;7:e29665.

12 Lightwood J, Glantz S. Effect of the Arizona tobacco control program on cigarette consumption and healthcare expenditures. Soc Sci Med 2011;72:166-72. 
13 Lightwood J, Glantz SA. The effect of the California tobacco control program on smoking prevalence, cigarette consumption, and healthcare costs: 1989-2008. PLoS One 2013;8:e47145.

14 Abadie A, Diamond A, Hainmueller J. Synthetic control methods for comparative case studies: estimating the effect of California's tobacco control program. J Am Stat Assoc 2010;105:493-505.

15 Centers for Disease Control and Prevention, Behavioral Risk Factor Surveillance System. BRFSS prevalence \& trends data: Centers for Disease Control and Prevention, National Centerfor Chronic Disease Prevention and Health Promotion, Division of Population Health, 2017. Available: https://www.cdc.gov/brfss/brfssprevalence/index. html

16 U.S. Census Bureau. 1980 census of population. General population characteristics. table 67 . Persons by age, race, Spanish origin, and sex, for states: 1980: U.S. department of Commerce, Bureau of the census, 1983. Available: https://www2.census.gov/prod2/decennial/ documents/1980/1980censusofpopu8011u_bw.pdf

17 U.S. Census Bureau. 1990 census of population. General population characteristics. Table 262. Age and sex by race and Hispanic origin: 1990: U.S. department of Commerce, Bureau of the census, 1990 Available: https://www2.census.gov/library/publications/decennial/ 1990/cp-1/cp-1-1.pdf

18 U.S. Census Bureau. Summary population and housing characteristics, United States: 2000. Table 1. Age and sex: 2000; table 2. race and Hispanic or Latino: 2000: U.S. department of Commerce, Bureau of the census, 2000. Available: https://www. census.gov/prod/cen2000/phc-1-1-pt1.pdf

19 U.S. Census Bureau. Summary population and housing characteristics, United States: 2010. Table 1. Age and sex: 2010; Table 2. Race and Hispanic or Latino: 2010: U.S. Department of Commerce, Bureau of the Census; 2010 [accessed 2019 November 15]. Retrieved from. Available: https://www2.census.gov/library/ publications/2012/dec/cph-1-1.pdf

20 U.S. Census Bureau. Current population survey. Annual Social and Economic (ASEC) Supplement. Historical income tables: households1984 to 2017. Table H-8B. Median household income by state - 3 year average: U.S. Department of Commerce, Bureau of the Census,
2017. Available: https://www.census.gov/data/tables/time-series/ demo/income-poverty/historical-income-households.html

21 U.S. Census Bureau. Current population survey. Annual Social and Economic (ASEC) Supplement. Historical poverty tables: people and families - 1959 to 2018. Table 21. Number of poor and poverty rate, by state: U.S. Department of Commerce, Bureau of the Census; 2018 [accessed 2019 November 15]. Retrieved from. Available: https://www.census.gov/data/tables/time-series/demo/incomepoverty/historical-poverty-people.html

22 Global Health Data Exchange. GBD results tool Seattle, WA: Institute for health metrics and evaluation, 2019. Available: http://ghdx. healthdata.org/gbd-results-tool

23 Centers for Medicare and Medicaid Services. Health expenditures by state of residence, 1991-2014: U.S. Centers for Medicare \& Medicaid Services, 2017. Available: https://www.cms.gov/Research-StatisticsData-and-Systems/Statistics-Trends-and-Reports/NationalHealthEx pendData/NationalHealthAccountsStateHealthAccountsResidence. html

24 Abadie A, Gardeazabal J. The economic costs of conflict: a case study of the Basque country. Am Econ Rev 2003;93:113-32.

25 U.S, Bureau of Labor Statistics. Databases, tables \& calculators by subject Washington, DC: U.S. Bureau of Labor Statistics; n.d, 2019. Available: https://www.bls.gov/data/

26 Miller VP, Ernst C, Collin F. Smoking-attributable medical care costs in the USA. Soc Sci Med 1999;48:375-91.

27 Nonnemaker J, Rostron B, Hall P, et al. Mortality and economic costs from regular cigar use in the United States, 2010. Am J Public Health 2014;104:e86-91.

28 Food and Drug Administration, HHS. Required warnings for cigarette packages and advertisements. final rule. Fed Regist 2011;76:36628-777.

29 Masters R, Anwar E, Collins B, et al. Return on investment of public health interventions: a systematic review. J Epidemiol Community Health 2017;71:827-34.

30 Xu X, Bishop EE, Kennedy SM, et al. Annual healthcare spending attributable to cigarette smoking: an update. Am J Prev Med 2015;48:326-33. 